\title{
EMPREGO DE VIDEOAULAS NO ENSINO-APRENDIZAGEM DA DISCIPLINA DE TÉCNICA DIETÉTICA
}

Wanessa Terra Oliveira ${ }^{1}$, Tiago Francisco Vicença ${ }^{2}$, Virgínia Souza Santos ${ }^{3}$

\section{RESUMO}

A inserção de novas estratégias de ensino por meio das Tecnologias da Informação e Comunicação gera maior integração entre alunos e professores, facilita o processo de ensino-aprendizagem, além de propiciar um ambiente mais atrativo e dinâmico. O objetivo deste trabalho foi avaliar o emprego de videoaulas no ensino-aprendizagem da disciplina de Técnica Dietética para o curso de Nutrição. Desenvolveram-se videoaulas sobre os conteúdos da disciplina que foram compartilhadas durante as aulas, em um canal no Youtube e no Facebook. Compararam-se as médias finais das notas (sem e com intervenção) pelo teste $T$ de Student a $5 \%$ de significância. A média das notas foi maior no período com intervenção $(p<0,05)$. Os discentes mencionaram que a mesma metodologia poderia ser adotada nas demais disciplinas. Concluiu-se que as videoaulas auxiliaram no processo de ensino-aprendizagem e podem ser utilizadas como uma ferramenta que permite aos estudantes a apropriação de conhecimentos.

Palavras-chave: Ciências da Nutrição. Tecnologia da Informação. Ensino superior.

\section{Como citar este documento - ABNT}

OLIVEIRA, Wanessa Terra; VICENÇA, Tiago Francisco; SANTOS, Virgínia Souza. Emprego de videoaulas no ensino-aprendizagem da disciplina de Técnica Dietética. Revista Docência do Ensino Superior, Belo Horizonte, v. 10, e020179, p. 1-19, 2020. DOI: https://doi.org/10.35699/2237-5864.2020.20179.

Recebido em: 27/04/2020 Aprovado em: 25/05/2020 Publicado em: $15 / 09 / 2020$

\footnotetext{
${ }^{1}$ Universidade Federal de Viçosa (UFV), Campus Rio Paranaíba, Rio Paranaíba, MG, Brasil. ORCID ID: https://orcid.org/0000-0003-1041-5181. E-mail: wanessaterra@outlook.com. ${ }^{2}$ Universidade Federal de Viçosa (UFV), Campus Rio Paranaíba, Rio Paranaíba, MG, Brasil. ORCID ID: https://orcid.org/0000-0002-4987-2761. E-mail: tiagovicenca@hotmail.com. ${ }^{3}$ Universidade Federal de Viçosa (UFV), Campus Rio Paranaíba, Rio Paranaíba, MG, Brasil. ORCID ID: https://orcid.org/0000-0002-6665-8097. E-mail: virginiasantos@ufv.br.
} 


\section{EMPLEO DE CLASES DE VIDEO EN LA ENSEÑANZA Y APRENDIZAJE DE LA ASIGNATURA DE LA TÉCNICA DIETÉTICA}

\section{RESUMEN}

La inserción de nuevas estrategias de enseñanza a través de las Tecnologías de la Información y la Comunicación genera una mayor integración entre estudiantes y docentes, facilita el proceso de enseñanza-aprendizaje, además de proporcionar un entorno más atractivo y dinámico. El objetivo de este trabajo fue evaluar el uso de clases de video en la enseñanza-aprendizaje de la asignatura de la técnica dietética para la carrera de Nutrición. Las clases de video se desarrollaron sobre los contenidos de la asignatura que se compartieron durante las clases y en un canal en Youtube y Facebook. Los puntajes promedio finales se compararon (sin y con intervención) mediante la prueba $T$ de Student con un nivel de significación del 5\%. El puntaje promedio fue mayor en el período de intervención ( $p<0.05$ ). Los estudiantes mencionaron que la misma metodología podría adoptarse en otras asignaturas. Se concluyó que las clases de video ayudaron en el proceso de enseñanza-aprendizaje y se pueden usar como una herramienta que permite a los estudiantes obtener el conocimiento apropiado.

Palabras clave: Ciencias de la Nutrición. Tecnología de la Información. Enseñanza superior.

\section{USE OF VIDEO LESSONS IN THE TEACHING-LEARNING PROCESS OF DIETARY TECHNIQUE DISCIPLINE}

\section{ABSTRACT}

The insertion of new teaching strategies through Information and Communication Technologies generates a higher integration between students and teachers, facilitates the teaching-learning process and, besides, provides a more attractive and dynamic environment. The objective of this work was to evaluate the use of video lessons in the teaching-learning process of Dietetic Technique discipline for the Nutrition course. Video lessons developed on the contents that were shared during classes, on a channel on YouTube and Facebook. Final average grades compared (with and without intervention) by the Student's $T$ test at a $5 \%$ significance level. The average grade was higher in the intervention period $(p<0.05)$. The students mentioned that the same methodology could be adopted in other disciplines. It concluded that video lessons help in the teaching learning process and can be used as a tool that allows students to appropriate knowledge.

Keywords: Nutritional Sciences. Information Technology. Higher education. 


\section{INTRODUÇÃO}

A didática convencional que usa métodos expositivos, na qual o professor é o possuidor da informação e o aluno é o receptor, não possibilita adequadamente o processo de ensinoaprendizagem (PIMENTEL, 2016). Tal limitação da abordagem tradicional faz emergir novas estratégias e meios de comunicação como complemento à ação do professor em sua prática docente. A crescente difusão das tecnologias provocou mudanças em todas as dimensões, inclusive na educação (BRAGA, 2013; SILVA; LINS; LEÃO, 2019).

A diversificação das metodologias didáticas propicia o compartilhamento de informações e a criação de novos materiais educativos que podem contribuir para o avanço científico do ensino (PIMENTEL, 2016). O uso das tecnologias é de grande importância para a construção do conhecimento, uma vez que elas desencadeiam diferentes comportamentos nos indivíduos e provocam cenários culturais inovadores. Com inúmeros recursos de comunicação, torna-se necessário um novo modelo de ensino-aprendizagem com posturas reformuladas tanto do docente quanto do discente para que haja um processo construtivo e integral do conhecimento (OLIVEIRA et al., 2018).

As Tecnologias de Informação e Comunicação (TICs) são reconhecidas como todas as tecnologias que facilitam a troca de informações por meio da comunicação eletrônica e que podem contribuir com o processo de ensino-aprendizagem (AGÊNCIA BRASILEIRA DE DESENVOLVIMENTO INDUSTRIAL, 2010). As TICs englobam o ensino pela tecnologia por diferentes formas de disseminação do conhecimento, como: a internet; dispositivos eletrônicos, como computadores, celulares, tablets e recursos audiovisuais; entre outros (CAMARGO; ITO, 2012; VASCONCELOS; OLIVEIRA, 2017).

Por meio das TICs é possível gerar integração entre alunos e professores para maior aquisição de conhecimento, além de simplificar o processo de avaliação e propiciar um ensino mais atrativo, dinâmico e moderno para ambos (SOARES; MENDES, 2019). A utilização de videoaulas é uma estratégia que permite o ensino com o emprego dessas novas metodologias durante as aulas. Isso porque aproxima a sala de aula do cotidiano no qual o aluno está inserido e traz experiências sensoriais como o visual, a linguagem falada, a linguagem musical e a escrita, além de combinar o sensorial, o emocional e o intuitivo para atingir o racional (MORAN, 1995).

$\mathrm{Na}$ formação de nutricionistas, as TICs podem ser empregadas em diversas áreas. A disciplina de Técnica Dietética aproxima os graduandos dos alimentos e compreende o estudo dos processos culinários aos quais os alimentos são submetidos, desde a seleção até as modificações sofridas para o consumo, com o objetivo de manter o valor nutricional e atingir as características sensoriais desejadas (BENETTI et al., 2013; DOMENE, 2011). 
De acordo com Oliveira (2015), a reduzida carga horária em sala de aula dificulta a apropriação de conhecimentos, o que pode ser solucionado por meio das TICs que oferecem recursos didáticos adequados e propiciam maior aprendizagem. É o caso da disciplina de Técnica Dietética, que possui um extenso conteúdo curricular e que inclui tópicos aprofundados sobre as modificações que os alimentos sofrem durante seu pré-preparo e preparo. Muitos estudantes não conseguem compreender estas alterações somente no período das aulas. Desse modo, exemplos práticos, palpáveis e visuais, por meio de videoaulas, poderão permitir a apropriação dos conhecimentos, contribuir para o exercício pleno da profissão e servir como ferramentas para facilitar o processo ensino-aprendizagem de Técnica Dietética para graduandos em Nutrição. Entretanto, observa-se que a literatura apresenta escassez de estudos no âmbito das TICs para o curso de Nutrição, principalmente acerca da disciplina de Técnica Dietética. Portanto, este trabalho teve como objetivo avaliar o emprego de videoaulas no ensino-aprendizagem de Técnica Dietética.

\section{METODOLOGIA}

A pesquisa de intervenção, com abordagem descritiva, analítica qualitativa e quantitativa, foi realizada em 2019, com a participação dos discentes matriculados na disciplina de Técnica Dietética I do curso de Nutrição da Universidade Federal de Viçosa - Campus Rio Paranaíba, e contemplou quatro fases, conforme descrição a seguir.

Fase 1: houve definição dos temas para a elaboração das videoaulas. Além disso, houve revisão bibliográfica, elaboração dos roteiros, gravação e edição das imagens e de linguagem (códigos e áudios) pelos softwares Adobe Photoshop versão CS6, Adobe Lightroom versão 5, Microsoft Power Point versão 2016 e o aplicativo on-line Biteable Video Maker. Posterior ao desenvolvimento das videoaulas, criou-se um canal no Youtube denominado "Nutrindo o Conhecimento" para o compartilhamento do material. Para facilitar o acesso ao conteúdo, também se criou uma página no Facebook com a mesma denominação do canal. As videoaulas foram desenvolvidas por discentes que já haviam cursado a disciplina de Técnica Dietética I, sob a orientação do professor responsável pela disciplina.

Fase 2: houve a caracterização sociodemográfica dos estudantes que cursavam a disciplina Técnica Dietética I no segundo semestre de 2019. Utilizou-se um questionário (Apêndice A), elaborado pelos autores, embasado nos fatores que influenciam o acesso às TICs, de acordo com a literatura consultada para o planejamento do estudo. Esse questionário abordou a data de nascimento, e, nas sete questões semiestruturadas, obtiveram-se informações quanto ao sexo, ao acesso à internet, aos equipamentos tecnológicos disponíveis e às principais fontes para estudos e elaboração de trabalhos acadêmicos. Havia, também, um espaço para a descrição das necessidades de outras metodologias de ensino. 
Fase 3: ocorreu a exibição das videoaulas desenvolvidas para o compartilhamento dos conteúdos da disciplina de forma atrativa e inovadora. Ao final de cada aula, a videoaula era exibida por meio de um datashow, de acordo com o conteúdo abordado naquele dia. $\mathrm{O}$ link da videoaula no canal do Youtube era disponibilizado para que os alunos revissem o conteúdo e a utilizassem como ferramenta de estudo para as atividades avaliativas.

O Quadro 1 relaciona a abordagem dos materiais que focou nas propriedades funcionais, nas técnicas de preparo e nas modificações decorrentes do preparo dos alimentos, de acordo com os conteúdos descritos no programa analítico da disciplina.

\begin{tabular}{|c|c|c|}
\hline Temas & Conteúdo abordado & Duração (minutos) \\
\hline Açúcares & Videoaula 1 - O açúcar e suas variedades & $2: 55$ \\
\hline \multirow{2}{*}{ Cereais } & Videoaula 2 - Arroz: estrutura do grão e suas \\
& variedades & $2: 45$ \\
\cline { 2 - 3 } & Videoaula 3 - Gelatinização do amido & $3: 11$ \\
\hline Carnes & Videoaula 4 - Conceituação e composição da carne & $3: 41$ \\
\hline Pigmentos e & Videoaula 5 - Carotenoides & $3: 48$ \\
\hline Vegetais & Videoaula 8 - Conceituação & $3: 07$ \\
\hline Frutas e Hortaliças & Videoaula 6 - Aquisição, conservação e higienização & $3: 12$ \\
\hline Leguminosas & Videoaula 7 - Leguminosas e suas variedades & $2: 22$ \\
Óleos e Gorduras & Videoaula 10 - Ponto de fumaça & $2: 38$ \\
& Videoaula 11 - A estrutura do ovo & $1: 27$ \\
\hline Ovos & Videoaula 12 - Teste: Ovo velho versus ovo fresco & $2: 37$ \\
& Videan 9 - Classificacao & $1: 39$ \\
\hline
\end{tabular}

Quadro 1 - Temas e conteúdo das videoaulas desenvolvidas para o emprego na disciplina de Técnica Dietética I da Universidade Federal de Viçosa - Campus Rio Paranaíba, 2020.

Fonte: elaborado pelos autores, 2020.

Fase 4: houve a avaliação do emprego dos materiais elaborados por meio do rendimento acadêmico dos discentes obtido pela plataforma de notas da Universidade Federal de Viçosa. Comparou-se a média da nota final dos alunos matriculados em 2018 (sem utilização das TICs) com os resultados dos discentes que cursavam a disciplina em 2019 (com utilização das TICs). Em ambos os períodos, a disciplina foi ministrada pela mesma professora, para estudantes do curso de Nutrição, matriculados no quarto período e com o mesmo conteúdo programático e tipos de avaliações. Após a intervenção, utilizou-se um questionário (Apêndice B) elaborado pelos autores, embasado na literatura observada para delineamento do estudo, composto por quatro questões. O instrumento analisou a contribuição das videoaulas para a aprendizagem, bem como o conteúdo, a qualidade e a metodologia, a opinião dos discentes sobre o emprego da mesma metodologia em outras disciplinas e sugestões de aperfeiçoamento. 
As coletas de dados (Fase 2 e Fase 4) foram realizadas por meio de questionários autoaplicáveis semiestruturados via internet pelo Google Docs, com um tempo médio de resposta de 15 minutos. O estudo respeitou todos os preceitos éticos com a participação voluntária e o sigilo das informações e foi aprovado pelo Comitê de Ética da Universidade Federal de Viçosa, sob o parecer número 3.331.090. Foram incluídos todos os alunos que cursavam a disciplina em 2019 e que aceitaram participar do estudo.

Os dados foram analisados descritivamente por meio de médias e desvio padrão, frequências absolutas e relativas. Compararam-se as médias finais das notas pelo teste $\mathrm{T}$ de Student a 5\% de significância no software Statistical Package for the Social Sciences (SPSS), versão 22.0 .

\section{RESULTADOS E DISCUSSÃO}

O canal do Youtube no qual foram disponibilizadas as videoaulas possuía 9.119 visualizações até junho de 2020, e a página no Facebook apresentava 221 curtidas no mesmo período.

Fernandes (2011) e Juliani et al. (2012) apontam que as redes sociais podem ser exploradas como ferramentas pedagógicas, pois, além de fornecerem uma importante troca de informação, promovem a colaboração no processo educativo e permitem que os indivíduos tenham uma visão crítica e reflexiva dos conhecimentos. O Facebook colabora na aprendizagem dos discentes, além de trazer estratégias aos docentes por disponibilizar e ampliar as percepções sobre o conteúdo abordado em páginas e grupos de forma colaborativa, o que expande a troca de informação e contribui para a formação profissional (LINHARES; CHAGAS, 2015).

Todos os dados dos participantes do estudo foram coletados por meio de formulários online desenvolvidos na plataforma Google Docs. De acordo com Faleiros et al. (2016), a utilização de tais formulários para a realização de pesquisas surge como uma ferramenta que possibilita economia, maior velocidade de captação de informações, que pode aumentar o número de respostas obtidas, além de uma maior praticidade e comodidade aos participantes.

Na fase de intervenção participaram 24 estudantes, com idade média de 21 anos, dos quais $87,5 \%(n=21)$ eram do sexo feminino. Todos participantes possuíam acesso à internet no domicílio, computador/notebook e dispositivos móveis (tablets ou smartphones).

A disponibilidade de equipamentos e acesso à internet coadunam com os dados do Comitê Gestor da Internet no Brasil (2019), que apontam que $67,5 \%$ das residências brasileiras (46,5 milhões de domicílios) possuem acesso à internet, e que este número é crescente a cada ano. O mesmo Comitê descreve que o uso do computador de mesa tem diminuído 
significativamente, uma vez que em 2018 a maioria das residências possuía notebooks e tablets (COMITÊ GESTOR DA INTERNET NO BRASIL, 2019).

Quando questionados sobre as principais fontes para estudo e trabalhos acadêmicos, as mais citadas foram o Youtube, livros, artigos e periódicos e e-books. Dentre os avaliados, $83,3 \%(n=20)$ utilizavam as redes sociais (Facebook, YouTube e Instagram) para o ensinoaprendizagem, o que demonstra que as plataformas virtuais têm sido um apoio aos estudos durante a graduação. Sobre as metodologias de ensino, 66,7\% $(n=16)$ descreveram a necessidade de outros formatos além do método expositivo, como videoaulas, vídeos interativos e aulas mais dinâmicas e práticas.

Tais resultados convergem com dados de estudos recentes que descrevem que os jovens são habituados a utilizar a internet para sanar dúvidas, além de se apropriarem das redes sociais para os estudos e relacionamentos (FERREIRA; CASTIGLIONE, 2017; LEMUS, 2017; SPIZZIRRI et al., 2012).

Segundo Gabriel (2013), o ensino convencional tem caído em desuso frente às diversas maneiras de estimular o processo de aprendizagem, que envolve cada vez mais as tecnologias digitais. Este fato direciona para a necessidade de diversificar as estratégias que condicionam a aprendizagem global e crítica. $O$ estudante contemporâneo adquiriu um perfil diferenciado, com exigências, necessidades e perspectivas específicas quanto ao docente e à forma de ensino disponibilizada.

Nesse sentido, as TICs serão uma alternativa para a aprendizagem e exercem papel fundamental para o desenvolvimento de uma visão crítica, além de serem uma ferramenta de apoio para a orientação dos acadêmicos (CAMARGO; ITO, 2012; VASCONCELOS; OLIVEIRA, 2017).

Após a utilização das videoaulas, $95,8 \% \quad(n=23)$ dos discentes apontaram que elas cooperaram para sua aprendizagem e sugeriram que essa metodologia poderia ser adotada em todas as disciplinas da matriz curricular do curso de Nutrição, com destaque para as disciplinas de Patologia da Nutrição e Dietoterapia, Bioquímica, Fisiologia Humana, Anatomia Humana, Imunologia, Avaliação Nutricional, Nutrição Humana, Técnica Dietética II e Gastronomia. Isso pode ser visto na resposta de dois acadêmicos às questões abertas dos questionários:

"Foi um complemento muito bom para os estudos, sugiro que tenha para todas as matérias, os vídeos resumidos auxiliam no aprendizado $e$ entendimento" (Participante 4).

"Com certeza é válido ser aplicada em todas as disciplinas, principalmente as que têm um maior grau de dificuldade" (Participante 20). 
As sugestões dos participantes 4 e 20 de inclusão dessa metodologia em outras disciplinas concernem com os resultados de outros estudos que apontam a eficiência das TICs na aprendizagem de diversas outras áreas do ensino superior, como no ensino de Bioquímica para o curso de Química (LIMA, 2017), Anatomia para o curso de Medicina (MARKER et al., 2012), Educação Nutricional para o curso de Nutrição (DAUN; GAMBARDELLA, 2016) e no estudo de Cálculo por estudantes do ensino superior (SANTOS; LOPO; SANTOS, 2019).

Comparando o segundo semestre de 2018 (sem utilização das TICs) e o segundo semestre de 2019 (com utilização das TICs), notou-se que a média das notas finais dos discentes matriculados na disciplina foi maior no período com intervenção $(p<0,05)$, conforme dados da Tabela 1, demonstrando a eficácia da metodologia na evolução dos resultados. Segundo Alves, Melo e Melo (2009) a anologia entre a pontuação obtida em dois momentos (antes e depois da intervenção) pressupõe um resultado assertivo da metodologia empregada.

\begin{tabular}{cccc}
\hline Período da avaliação & $\mathrm{n}$ & Notas & Valor de $\mathrm{p}$ \\
\hline Sem utilização das TICs & 23 & $70,47 \pm 7,45$ & \\
Com utilização das TICs & 24 & $82,20 \pm 6,82$ & 0,000 \\
\hline
\end{tabular}

Tabela 1 - Média e desvio padrão das notas obtidas pelos discentes na disciplina de Técnica Dietética I da Universidade Federal de Viçosa - Campus Rio Paranaíba, entre 2018 e 2019.

Fonte: elaborada pelos autores, 2020.

Torres e Santos (2014), ao utilizarem videoaulas em uma disciplina sobre Terapia Nutricional na Universidade de Brasília, perceberam que elas foram ferramentas eficazes na formação de profissionais da Saúde, tendo em vista que, ao comparar as notas dos estudantes, observou-se uma média maior $(6,91 \pm 1,17)$ para os que utilizaram o material do que a média $(5,48 \pm 1,76)$ dos que não o fizeram. Além disso, o mesmo estudo descreveu que quanto mais vezes os acadêmicos visualizaram as videoaulas, maior foram as notas das atividades avaliativas e a pontuação final da disciplina.

Os resultados supracitados confirmam que o ensino medidado pelas TICs proporciona o maior aproveitamento do conteúdo ministrado e possibilita a aprendizagem, assim como reflete em um ensino de maior qualidade (ALMEIDA, 2016; VOSGERAU; ROSSARI, 2017). Souza et al. (2017) apontam que o ensino da Nutrição por meio da utilização das TICs viabiliza a aquisição de competências e formação de habilidades essenciais para a atuação dos futuros profissionais da área da Saúde.

Entretanto, destaca-se que o processo de ensino-aprendizagem sofre influência de diversos fatores, como a forma de ingresso no ensino superior (Exame Nacional do Ensino Médio, reingresso, transferência), tipo de disciplina, frequência às aulas e uso da biblioteca e de Ambientes Virtuais de Aprendizagem (AVA) (AUGUSTO JUNIOR et al., 2019). Além disso, a utilização das tecnologias no contexto das Ciências da Nutrição deve ser ponderada, posto 
que o desfecho positivo na aprendizagem é condicionado ao acesso aos equipamentos, à habilidade de manejo, ao envolvimento e às condições socioeconômicas (CURIONI; BRITO; BOCCOLINI, 2013).

Em 1995 já se afirmava que a videoaula auxiliava o docente, gerava um maior interesse dos discentes sem modificar a relação pedagógica e introduzia as novas questões no processo educacional. Para o estudante, esta metodologia significa um lazer e não uma aula, pois cria uma ponte entre os vídeos e as aulas práticas (MORAN, 1995).

A nota média atribuída pelos acadêmicos quanto ao conteúdo, à metodologia e à qualidade dos materiais utilizados foi de 8,80 pontos. Outro estudo realizado em uma Universidade Federal utilizou seis videoaulas no ensino-aprendizagem da disciplina de Nutrição Humana e obteve uma média de 8,97 pontos ao avaliar a satisfação dos estudantes quanto aos materiais ofertados (TORRES; ABBAD; SANTOS, 2014). Torres e Santos (2014), ao disponibilizar videoaulas para uma disciplina de Nutrição focada na Terapia Nutricional ofertada para os cursos de Enfermagem, Farmácia, Fisioterapia, Saúde Coletiva e Terapia Ocupacional na Universidade de Brasília, obtiveram nota semelhante em relação à importância das videoaulas para o aprendizado $(8,50)$.

Percebeu-se a efetividade da utilização das videoaulas no ensino-aprendizagem, pois aqueles que assistiram as videoaulas e que tiveram acesso a estes materiais para estudar para as atividades avaliativas obtiveram melhores resultados. Além disso, os relatos dos acadêmicos demonstram que os materiais foram eficazes no processo de construção do conhecimento, tendo em vista o desejo de expandi-los para outros componentes curriculares. De acordo com Mayer e Moreno (2003), as videoaulas agradam e permitem maior concentração dos estudantes por apresentarem áudio e imagem em única mídia, o que exige menor trabalho intelectual.

Entretanto, algumas observações sugerem um maior aperfeiçoamento da qualidade e dos conteúdos, conforme relato dos participantes:

"Os vídeos são ótimos, sugiro criar uma caixinha de dúvidas em relação à matéria e depois elaborar vídeos contemplando as principais dúvidas" (Participante 19).

"Os vídeos foram muito rápidos, na aula às vezes não dava para ler tudo, mas em casa dá para ir pausando e assim ler tudo. O conteúdo me ajudou muito nas provas" (Participante 2 ).

"Os materiais são muito bons, mas acredito que para chegar à uma excelência nos vídeos falta uma fala, ou seja, uma narrativa dos processos que estão sendo expostos" (Participante 24). 
As narrativas dos estudantes reforçam as ideias de Dussel (2015), que cita que a colaboração entre usuários para estimular e desenvolver habilidades auxilia na criação de novos conhecimentos e que as TICs podem ser empregadas na formação de redes de espaços criativos.

Nesse mesmo sentido, o relato do participante 19 corrobora com as ideias de Kenski, Medeiros e Órdeas (2019), que afirmam que o ensino mediado pela tecnologia traz uma nova metodologia de ensino que permite o acesso a inúmeros conteúdos no domicílio do aluno. O novo ensejo do ensino digital propõe a formação do pensamento crítico e transforma o estudante no principal ator da construção do conhecimento. A relação professor e aluno passa a ter uma característica colaborativa, na qual ambos têm o papel de interagir e colaborar no processo de aprendizagem.

Os relatos dos participantes 2 e 24 reiteram a importância de algumas características básicas dos conteúdos digitais para atingir dois sentidos: a visão por meio da linguagem corporal, da imagem, do texto e do vídeo; e a audição mediante o som e as falas (KENSKI; MEDEIROS; ÓRDEAS, 2019).

Não obstante a tecnologia tenha sido cada vez mais utilizada como recurso pedagógico, garantir o acesso a ela ainda é a maior dificuldade. Mesmo que as próprias universidades ofereçam recursos tecnológicos dentro da sua estrutura, há muitos estudantes que não possuem acesso a esses equipamentos e à internet nos ambientes fora das instituições de ensino superior (RIBAS et al., 2017).

Embora as TICs tenham resultados positivos, Moran (2007) descreve que há situações de atraso existentes nas instituições educacionais e resistência entre os educadores quanto à introdução dessas tecnologias na educação brasileira. O professor continua tendo um papel essencial, não como transmissor do conhecimento, mas como mediador no acesso, ao ajudar os alunos a serem mais criteriosos nas escolhas dos conteúdos e a desenvolverem pensamentos críticos e construtivos.

Muitos professores ainda encontram um obstáculo didático cultural de inserção das TICs na sua prática diária, devido a estrutura física e dificuldades em romper com hábitos e costumes em sala de aula. Alguns profissionais relatam que seu uso é um desafio, pois mudar dá trabalho e demanda um maior tempo (SCHUHMACHER, 2014; SCHUHMACHER; ALVES FILHO; SCHUHMACHER, 2017).

As TICs não objetivam eliminar o uso de técnicas convencionais de ensino e pesquisa, mas podem ser incorporadas como um adicional ao processo educacional já existente. Sua introdução não tem o papel de substituir o trabalho do docente, mas de complementar sua atuação para efetivar a aprendizagem pelos alunos. Sendo agregadas às metodologias já 
utilizadas, as TICS contribuem para que haja um maior aprimoramento das técnicas de ensino de forma a atingir as competências desejadas (LOBO; MAIA, 2015).

As novas tecnologias podem trazer melhorias na área da educação, em especial no ensino superior, com metodologias de ensino de diferentes formas, apresentar uma nova concepção de aprender e ensinar com muito mais flexibilidade para a efetivação da aprendizagem (GESSER, 2012).

\section{CONSIDERAÇÕES FINAIS}

Todos os participantes do estudo tinham acesso às TICs e tal fator foi decisivo para o emprego da metodologia proposta. Os discentes atribuíram uma nota elevada aos materiais produzidos, descreveram que as videoaulas facilitaram a aprendizagem e sugeriram a inclusão dessa metodologia para outras disciplinas do curso de Nutrição.

O perfil atual dos discentes é voltado para tecnologia, o que facilita a integração com a metodologia proposta. A maioria dos estudantes destacou a utilização das redes sociais como ferramenta de estudos. Nesse sentido, em tempos em que as relações humanas se convergem para a mediação tecnológica, a utilização das TICs surge como uma alternativa de metodologia de ensino frente ao declínio dos métodos tradicionais de ensino.

As videoaulas foram eficientes no ensino-aprendizagem da disciplina de Técnica Dietética, pois contribuíram para a melhora do desempenho acadêmico dos estudantes e tornaram as aulas mais dinâmicas, fato este que corrobora com o atual cenário e o perfil dos universitários.

Sugere-se a expansão dessas ferramentas educacionais, por meio da criação de outros tipos de materiais para outras disciplinas do Curso de Nutrição, para uma maior integração entre os docentes e discentes, bem como um estímulo à motivação, à criatividade, ao pensamento crítico e a uma participação mais ativa durante a formação acadêmica.

\section{REFERÊNCIAS}

AGÊNCIA BRASILEIRA DE DESENVOLVIMENTO INDUSTRIAL - ABDI. Tecnologias de Informação e Comunicação - TIC: Sistemas Aplicados a Segurança Pública. Brasília: ABDI, 2010. Disponível em:

https://livroaberto.ibict.br/bitstream/1/536/1/Caderno\%20Tem\%C3\%A1tico\%20TIC\%20\%203\%20\%28Vers\%C3\%A30\%20Final\%29-

\%20Sistemas\%20Aplicados\%20a\%20Seguran\%C3\%A7a\%20Publica.pdf. Acesso em: 19 fev. 2020.

ALMEIDA, Hélio Mangueira de. O uso de celulares, tablets e notebooks no ensino da matemática. Revemat, Florianópolis, v. 11, n. 2, p. 318-327, 2016. Disponível em: 
https://periodicos.ufsc.br/index.php/revemat/article/view/1981-1322.2016v11n2p318. Acesso em: 29 jun. 2020. DOI: http://dx.doi.org/10.5007/1981-1322.2016v11n2p318.

ALVES, Luciene; MELO, Dayane Helena Cardoso; MELO, Juliano Ferreira de. Análise do conhecimento nutricional de adolescentes, pré e pós atividade educativa. Revista Em Extensão, Uberlândia, v. 8, n. 2, p. 68-79, 2009. Disponível em:

http://www.seer.ufu.br/index.php/revextensao/article/view/20532/10956. Acesso em: 28 jun. 2020. DOI: https://doi.org/10.14393/REE.

AUGUSTO JUNIOR, Roberto Gonçalves et al. Descoberta de conhecimento para identificação de fatores que influenciam o desempenho discente. Informática na Educação: Teoria \& Prática, Porto Alegre, v. 22, n. 3, p. 58-82, 2019. DOI: https://doi.org/10.22456/19821654.93052.

BENETTI, Gisele Bizon et al. Manual de Técnicas Dietéticas. São Paulo: Yendis, 2013.

BRAGA, Denise Bértoli. Ambientes digitais: reflexões teóricas e práticas. São Paulo: Editora Cortez, 2013.

CAMARGO, Amanda Leite; ITO, Márcia. Utilização das tecnologias de informação e comunicação na área da Saúde: uso das redes sociais pelos médicos. Journal of Health Informatics, São Paulo, v. 4, n. 4, p. 165-169, 2012. Disponível em: http://www.jhisbis.saude.ws/ojs-jhi/index.php/jhi-sbis/article/view/220/144. Acesso em: 19 fev. 2020.

COMITÊ GESTOR DA INTERNET NO BRASIL. Pesquisa sobre o uso das tecnologias de informação e comunicação nos domicílios brasileiros: TIC domicílios 2018. São Paulo: Comitê Gestor da Internet no Brasil, 2019. Disponível em: https://www.cetic.br/media/docs/publicacoes/2/12225320191028tic_dom_2018_livro_eletronico.pdf. Acesso em: 28 jun. 2020.

CURIONI, Cíntia Chaves; BRITO, Flavia dos Santos Barbosa; BOCCOLINI, Cristiano Siqueira. O uso de tecnologias de informação e comunicação na área da Nutrição. Jornal Brasileiro de TeleSSaúde, Rio de Janeiro, v. 2, n. 3, p; 104-111, 2013. Disponível em: https://www.epublicacoes.uerj.br/index.php/jbtelessaude/article/view/8630/6510. Acesso em: 04 jul. 2020. DOI: https://doi.org/10.12957/jbrastele.2013.8630.

DAUN, Felipe; GAMBARDELLA, Ana Maria Dianezi. Extensão universitária na graduação em Nutrição: experiências de produção de vídeos educativos. Revista de Graduação USP, São Paulo, v. 1, n. 1, p. 101-105, 2016. Disponível em:

http://www.revistas.usp.br/gradmais/article/view/117737. Acesso em: 19 fev. 2020. DOI: https://doi.org/10.11606/issn.2525-376X.v1i1p101-105.

DOMENE, Semíramis Martins Álvares. Técnica Dietética: Teoria e Aplicações. Rio de Janeiro: Guanabara Koogan, 2011.

DUSSEL, Inés. La incorporación de TIC enlaformación docente de los países del Mercosur: estudios comparados sobre políticas e instituciones. Buenos Aires: Teseo, 2015. Disponível 
em: https://oei.org.ar/wp-content/uploads/2018/01/Incorporaci\%C3\%B3n-con-sentidopedag\%C3\%B3gico-de-TIC-en-la-formaci\%C3\%B3n-docente-de-los-pa\%C3\%ADses-delMercosur.pdf. Acesso em: 11 fev. 2020.

FALEIROS, Fabiana et al. Uso de questionário online e divulgação virtual como estratégia de coleta de dados em estudos científicos. Texto \& Contexto Enfermagem, Florianópolis, v. 25, n. 4, p. 1-6, 2016. Disponível em: https://www.scielo.br/scielo.php?pid=S010407072016000400304\&script=sci_abstract\&tlng=pt. Acesso em: 19 fev. 2020. DOI: http://dx.doi.org/10.1590/0104-07072016003880014.

FERNANDES, Luís. Redes sociais online e educação: contributo do Facebook no contexto das comunidades virtuais de aprendentes. Lisboa: Faculdade de Ciências e Tecnologia, Universidade Nova de Lisboa, 2011. 4 p. Ensaio. Disponível em: http://www.trmef.Ifernandes.info/ensaio_TRMEF.pdf. Acesso em: 19 fev. 2020.

FERREIRA, Gisele Martins dos Santos; CASTIGLIONE, Rafael Guilherme Mourão. TIC na educação: ambientes pessoais de aprendizagem nas perspectivas e práticas de jovens. Educação e Pesquisa, São Paulo, v. 44, 2017. Disponível em: https://www.scielo.br/scielo.php?pid=S151797022017005009101\&script=sci_abstract\&tlng=pt. Acesso em: 02 jul. 2020. DOI: http://dx.doi.org/10.1590/s1678-4634201702153673.

GABRIEL, Martha. Educar: a(r) evolução digital na educação. São Paulo: Saraiva, 2013.

GESSER, Verônica. Novas tecnologias e educação superior: Avanços, desdobramentos, implicações e limites para a qualidade da aprendizagem. Revista Iberoamericana de Informática Educativa, Ciudad Real, n. 16, p. 23-31, 2012. Disponível em: https://dialnet.unirioja.es/servlet/articulo?codigo=4095305. Acesso em: 10 jan. 2020.

JULIANI, Douglas Paulesky et al. Utilização das redes sociais na educação: guia para o uso do Facebook em uma instituição de ensino superior. Renote - Revista Novas Tecnologias na Educação, Porto Alegre, v. 10, n. 3, p. 1-10, 2012. Disponível em: https://seer.ufrgs.br/renote/article/view/36434/0. Acesso em: 20 jan. 2020. DOI: https://doi.org/10.22456/1679-1916.36434.

KENSKI, Vani Moreira; MEDEIROS, Rosangela Araújo; ORDÉAS, Jean. Ensino superior em tempos mediados pelas tecnologias digitais. Trabalho \& Educação, Belo Horizonte, v. 28, n. 1, p. 141-152, 2019. Disponível em:

https://periodicos.ufmg.br/index.php/trabedu/article/view/9872/9932. Acesso em: 03 jul. 2020. DOI: https://doi.org/10.35699/2238-037X.2019.9872.

LEMUS, Magdalena. Jóvenes frente al mundo: Las tecnologías digitales como soporte de la vida cotidiana. Revista Latinoamericana de Ciencias Sociales, Niñez y Juventud, Manizales, v. 15, n. 1, p. 161-172, 2017. Disponível em: https://pesquisa.bvsalud.org/controlecancer/resource/pt/biblio-836169. Acesso em: 01 jul. 2020. DOI: http://dx.doi.org/10.11600/1692715x.1510902022016. 
LIMA, Emmanuela Ferreira. O uso das TICs e da pesquisa como recursos pedagógicos no ensino de Bioquímica para o Curso de Licenciatura em Química. Revista de Graduação USP, São Paulo, v. 2, n. 2, p. 115-120, 2017. Disponível em:

http://www.revistas.usp.br/gradmais/article/view/123884. Acesso em: 15 fev. 2020. DOI: https://doi.org/10.11606/issn.2525-376X.v2i2p115-120.

LINHARES, Ronaldo Nunes; CHAGAS, Alexandre Meneses. Conectivismo e aprendizagem colaborativa em rede: o Facebook no ensino superior. Revista Lusófona de Educação, Aracaju, v. 29, n. 29, p.71-78, 2015. Disponível em: https://revistas.ulusofona.pt/index.php/rleducacao/article/view/5095. Acesso em: 23 jan. 2020.

LOBO, Alex Sander Miranda; MAIA, Luiz Cláudio Gomes. O uso das TICs como ferramenta de ensino-aprendizagem no ensino superior. Caderno de Geografia, Belo Horizonte, v. 25, n. 44, p. 16-26, 2015. Disponível em:

http://www.luizmaia.com.br/docs/cad_geografia_tecnologia_ensino.pdf. Acesso em: 8 jan. 2020. DOI: https://doi.org/10.5752/P.2318-2962.2015v25n44p16.

MARKER, David R. et al. Strategic improvements for gross anatomy web-based teaching. Anatomy Research International, Londres, v. 2012, p. 1-9, 2012. Disponível em: https://www.hindawi.com/journals/ari/2012/146262/. Acesso em: 19 fev. 2020. DOI: https://doi.org/10.1155/2012/146262.

MAYER, Richard E.; MORENO, Roxana. Nine ways to reduce cognitive load in multimedia learning. Educational Psychologist, Londres, v. 38, n. 1. p. 43-52, 2003. Disponível em: http://www.psychology.mcmaster.ca/bennett/psy720/readings/m1/m1r4.pdf. Acesso em: 02 jul. 2020. DOI: http://dx.doi.org/10.1207/S15326985EP3801_6.

MORAN, José Manuel. O vídeo na sala de aula. Comunicação \& Educação, São Paulo, n. 2, p. 27-35, 1995. Disponível em: https://www.revistas.usp.br/comueduc/article/view/36131. Acesso em: 19 fev. 2020. DOI: https://doi.org/10.11606/issn.2316-9125.v0i2p27-35.

MORAN, José Manuel. A educação que desejamos: novos desafios e como chegar lá. 2. ed. Campinas: Papirus, 2007.

OLIVEIRA, Cláudio de. TICs na educação: a utilização das Tecnologias da Informação e Comunicação na aprendizagem do aluno. Pedagogia em Ação, Belo Horizonte, v. 7, n. 1, p.75-95, 2015. Disponível em:

http://periodicos.pucminas.br/index.php/pedagogiacao/article/view/11019. Acesso em: 30 jun. 2020.

OLIVEIRA, Edilene Maria et al. Educação formal na construção do conhecimento e o papel potencializador das TICs no processo de aprendizagem. In: INTERNATIONAL CONGRESS OF KNOWLEDGE AND INNOVATION CIKI, 1., 2018, Guadalajara. Anais do IX Congresso Internacional de Conhecimento e Inovação. Guadalajara: Ciki, 2018. Disponível em: http://proceeding.ciki.ufsc.br/index.php/ciki/article/view/588. Acesso em: 24 jan. 2020. 
PIMENTEL, Nara. As Tecnologias de Informação e Comunicação (TIC) no ensino superior: a utopia da inovação pedagógica e da modernização. Revista de Educação Pública, [S.I.], v. 25, n. 59/2, p. 476-501, 2016. Disponível em:

http://www.periodicoscientificos.ufmt.br/ojs/index.php/educacaopublica/article/view/3831 . Acesso em: 19 fev. 2020. DOI: http://dx.doi.org/10.29286/rep.v25i59/2.3831.

RIBAS, Ana Carolina et al. O uso do aplicativo QR CODE como recurso pedagógico no processo de ensino e aprendizagem. Ensaios Pedagógicos, São Carlos, v. 7, n. 2, p. 12-21, 2017. Disponível em: http://www.opet.com.br/faculdade/revista-pedagogia/pdf/n14/n14artigo-2-O-USO-DO-APLICATIVO-QR-CODE.pdf. Acesso em: 02 jun. 2020.

SANTOS, Maria Cristina Elyote Marques; LOPO, Alexandre Boleira; SANTOS, Paulo César Marques de Andrade. Ensino e avaliação de cálculo diferencial e integral no ensino superior com TIC-Tecnologia da Informação e Comunicação. Brazilian Journal of Development, São José dos Pinhais, v. 5, n. 8, p. 11276-11287, 2019. Disponível em:

http://www.brazilianjournals.com/index.php/BRJD/article/view/2675. Acesso em: 22 jan. 2020. DOI: https://doi.org/10.34117/bjdv5n8-010.

SCHUHMACHER, Vera Rejane Niedersberg. Limitações da prática docente no uso das tecnologias da informação e comunicação. 2014. Tese (Doutorado em Educação Científica e Tecnológica) - Universidade Federal de Santa Catarina, Florianópolis, 2014. Disponível em: https://repositorio.ufsc.br/handle/123456789/129032. Acesso em: 21 jan. 2020.

SCHUHMACHER, Vera Rejane Niedersberg; ALVES FILHO, José de Pinho; SCHUHMACHER, Elcio. As barreiras da prática docente no uso das tecnologias de informação e comunicação. Ciência \& Educação Bauru, Bauru, v. 23, n. 3, p. 563-576, 2017. Disponível em: https://www.scielo.br/scielo.php?pid=S1516-73132017000300563\&script=sci_arttext. Acesso em: 09 fev. 2020. DOI: https://doi.org/10.1590/1516-731320170030002.

SILVA, Ivoneide Mendes; LINS, Walquíria Castelo Branco; LEÃO, Marcelo Brito Carneiro. Avaliação da aplicação da metodologia aprendizagem baseada em problemas na disciplina de tecnologia da informação e comunicação no ensino de química. Educación Química, México, v. 30, n. 3, p. 64-78, 2019. Disponível em:

http://www.scielo.org.mx/scielo.php?pid=S0187-893X2019000300064\&script=sci_arttext. Acesso em: 17 jan. 2020. DOI: http://dx.doi.org/10.22201/fq.18708404e.2019.3.68493.

SOARES, Luciana Maria de Morais Martins; MENDES, Rodrigo Farias Herculano. Smartphone, $Q R$ codegenerator e Google Forms na ensinagem do tronco encefálico em Neuroanatomia. Revista Docência do Ensino Superior, Belo Horizonte, v. 9 p. 1-17, 2019. Disponível em: https://periodicos.ufmg.br/index.php/rdes/article/view/12059. Acesso em: 01 fev. 2020. DOI: https://doi.org/10.35699/2237-5864.2019.12059.

SOUZA, Cláudio José et al. Experiência, alteridade e subjetividade: nexos com o ensino aprendizagem na graduação em Nutrição: relato de experiência. Euroupean Journal of Education Studies, Romênia, v. 3, n. 4, p. 383-393, 2017. Disponível em: https://www.oapub.org/edu/index.php/ejes/article/view/589. Acesso em: 22 fev. 2020. DOI: http://dx.doi.org/10.5281/zenodo.400273. 
SPIZZIRRI, Rosane Cristina Pereira et al. Adolescência conectada: mapeando o uso da internet em jovens internautas. Psicologia Argumento, [S.I.], v. 30, n. 69, 2012. Disponível em: https://periodicos.pucpr.br/index.php/psicologiaargumento/article/view/23288. Acesso em: 03 jul. 2020. DOI: https://doi.org/10.7213/psicolargum.v30i69.23288.

TORRES, Andreia Araujo Lima; ABBAD, Gardênia da Silva; SANTOS, Kelb Bousquet. Nível de satisfação de estudantes de saúde quanto ao uso de estratégias de ensino apoiadas por Tecnologias de Informação e Comunicação. Revista Eletrônica Gestão \& Saúde, Brasília, v. 5, p. 2313-2325, 2014. Disponível em:

https://periodicos.unb.br/index.php/rgs/article/download/969/839/. Acesso em: 04 jul. 2020.

TORRES, Andreia Araujo Lima; SANTOS, Kelb Bousquet. Formação de profissionais de saúde para atuarem na atenção às necessidades alimentares especiais. Revista Brasiliense de Nutrição, Brasília, v. 1, n. 1, p. 19 -36, 2014. Disponível em:

http://www.academia.edu/download/43901454/RBN_Artigo_Publicado_1.pdf. Acesso em: 01 jul. 2020. DOI: https://doi.org/10.1590/S1413-81232011000700010.

VASCONCELOS, Carlos Alberto de; OLIVEIRA, Eliane Vasconcelos. TIC no ensino e na formação de professores: reflexões a partir da prática docente. Revista Brasileira de Ensino Superior, Passo Fundo, v. 3, n. 1, p. 112-132, 2017. Disponível em: http://ri.ufs.br/jspui/handle/riufs/7122. Acesso em: 07 jan. 2020. DOI: http://dx.doi.org/10.18256/2447-3944/rebes.v7n1p112-132.

VOSGERAU, Dilmeire Sant'Anna Ramos; ROSSARI, Marilusa. Princípios orientadores de integração das tecnologias digitais ao projeto político-pedagógico. Revista Ibero-Americana de Estudos em Educação, Araraquara, v. 12, n. 2, p. 1020-1036, 2017. Disponível em: https://periodicos.fclar.unesp.br/iberoamericana/article/view/9051/6580. Acesso em: 03 jul. 2020. DOI: http://dx.doi.org/10.21723/riaee.v12.n2.9051. 


\section{APÊNDICE A - Questionário para a caracterização}

1. Data de nascimento:

2. Sexo:
○ Feminino;
- Masculino.

3. Você tem acesso à internet em casa?
○ Sim;
○ Não.

4. Você possui computador/notebook?
○ Sim;
○ Não.

5. Você possui dispositivo móvel (exemplos: smartphone/tablet) com acesso à internet? O Sim;

6. Selecione qual(is) a(s) sua(s) principal(is) fonte(s) de pesquisa para os estudos e elaboração de trabalhos acadêmicos:
- Livros;
- Artigos/ periódicos;
- E-books;
- Blogs;
○ Revistas;
○ Jornais;
o Programas de TV;
- Youtube;
- Outro(s):

7. Você utiliza as redes sociais para complementar o processo de ensino-aprendizagem? - Sim. Qual(is)?

○ Não.

8. Você gostaria de outras formas de apresentação para aprendizagem dos conteúdos, além do método de ensino-aprendizagem expositivo (slides e quadro)?
S Sim. Qual(is)?
○ Não. 
APÊNDICE B - Questionário para a avaliação do emprego das videoaulas no ensinoaprendizagem da disciplina de Técnica Dietética I

1. Os materiais usados em sala de aula contribuíram para a sua aprendizagem?
○ Sim;
○ Não.

2. Em uma escala de 0 a 10 , qual a nota em relação aos conteúdos, metodologia e qualidade dos materiais utilizados?

3. Essa metodologia usada poderá ser empregada em outra(s) disciplina(s)?
○ Sim. Qual(is)?
○ Não.

4. Deixe sugestões de possíveis melhorias para aperfeiçoamento dos conteúdos e das formas de abordagem. 


\section{Wanessa Terra Oliveira}

Graduanda em Nutrição na Universidade Federal de Viçosa (UFV), Campus Rio Paranaíba, Rio Paranaíba/MG.

wanessaterra@outlook.com.

\section{Tiago Francisco Vicença}

Bacharel em Nutrição pela Universidade Federal de Viçosa (UFV), Campus Rio Paranaíba, Rio Paranaíba/MG.

tiagovicenca@hotmail.com.

\section{Virgínia Souza Santos}

Doutora em Atenção à Saúde pela Universidade Federal do Triângulo Mineiro (UFTM); Mestre em Ciência e Tecnologia de Alimentos pelo Instituto Federal do Triângulo Mineiro (IFTM); Graduada em Nutrição pelo Centro Universitário de Patos de Minas (UNIPAM). Professora adjunta do Curso de Nutrição da Universidade Federal de Viçosa (UFV), Campus Rio Paranaíba, Rio Paranaíba/MG.

virginiasantos@ufv.br. 